\title{
Influence of the Cooling Environment on Cutting Temperature and Specific Energy when Turning AISI 4340 Steel
}

\author{
Christianne L. Soares ${ }^{1}$, Paulo E. de Faria ${ }^{2}$, Augusto M. Martins ${ }^{3}$, Antônio Carlos de \\ Andrade $^{4}$, Alexandre M. Abrão ${ }^{5 *}$ \\ ${ }^{1,2}$ Department of Production Engineering, Universidade Federal de Minas Gerais, AvenidaAntônio Carlos, 6627 Pampulha, \\ Belo Horizonte MG, CEP: 3120-901, Brazil \\ 3,4,5 Department of Mechanical Engineering, Universidade Federal de Minas Gerais, AvenidaAntônio Carlos, 6627 Pampulha, \\ Belo Horizonte MG, CEP: 3120-901, Brazil \\ *Email: abrao@ufmg.br
}

\begin{abstract}
Temperature monitoring and controlling is a critical aspect influencing the technical and economic success of metal cutting operations owing to the fact that it affects both the quality of the machined component and the performance of the cutting tool. The aim of this work is to investigate the influence of the cutting parameters on tool temperature when turning AISI 4340 steel under three cooling environments: flooding, minimal quantity lubrication and dry cutting. In addition to that, the specific cutting energy required under each cooling environment was measured using a modified impact testing machine, thus allowing the estimate of the temperature associated with the chip formation mechanism. Furthermore, it is aimed at verifying whether this test can replace force measurement using a dynamometer. The findings indicate that the lowest tool temperature was achieved under flood cooling, followed by minimum quantity lubrication and dry cutting. Inversely, lowest specific cutting energy was obtained when dry cutting, followed by minimum quantity lubrication and flooding, thus suggesting that the higher temperatures achieved under dry cutting aid the softening of the work material and the reduction of its shear strength.
\end{abstract}

Keywords-AISI 4340 steel, specific cutting energy, temperature, turning.

\section{INTRODUCTION}

The usage of cutting fluids aiming at reducing temperature in cutting zone was first reported by Taylor [1], who manage to increase cutting speed by $40 \%$ in turning with the provision of ordinary water as cutting fluid. Ever since, considerable progress has been achieved with regard to cutting fluids formulation and means of application, thus leading to increasing cutting tool life, superior surface finish [2], tighter dimensional accuracy, easiness of chip breakage and transportation [3], machined surface protection against corrosion and reduced cutting forces and energy consumption [4].

Despite the above mentioned benefits, approximately $85 \%$ of the cutting fluids used in industry is of mineral basis and therefore offers considerable risk to environment and occupational health and safety during their life cycle [5]. Prolonged contact of cutting fluids may cause dermatitis [6], skin and breathing problems [7], intoxication and cancer [8]. Furthermore, cutting fluid purchase, maintenance and disposal increase production costs. Boubekri, Shaikh \& Foster [8] estimate that between $7.5 \%$ and $20 \%$ of the production costs is related to cutting fluids, while the costs associated with cutting tools are approximately $4 \%$.

Hadad\&Sadeghi [2] highlight minimal quantity lubrication (MQL) as an important alternative to flood cooling due to the fact that it combines cooling function with extremely low fluid consumption, which ranges from 10 to $500 \mathrm{ml} / \mathrm{h}$. The influence of the cooling environment (flooding, MQL or dry cutting) on the machinability of TiAl4V when turning with polycrystalline diamond tools was investigated by Revankar et al. [9], who noticed that while MQL provided better surface finish (owing to the reduced friction between tool and workpiece), dry turning promoted higher surface hardness of the machined specimen due to the increase in workpiece temperature combined with higher plastic flow rate when cutting under this condition.

Cutting fluid application at the tool-chip or tool-workpiece interface directly affects cutting temperature. Varadarajan, Philip \&Ramamoorthy [10]performed turning trials using AISI 4340 steel as work material and reported lowest temperature using MQL in comparison with dry turning and flooding, under both low and high cutting speeds. The results are explained by the fact that cutting fluid droplets are capable of reaching the interface, making heat transfer more effective.

Work by Li and Liang [11] investigated the influence of cutting fluids on temperature when turning AISI 1045 steel dry, under flooding and using MQL. The cutting tool temperature was measured using an embedded thermocouple while cutting speed, feed rate and depth of cut were varied and the results indicated that tool temperature decreased by $22,1 \%$ for MQL and 
31,4\% when flood turning in comparison with dry cutting. Temperature reduction for MQL was attributed to both cooling and lubrication effects, however, temperature reduction under flooding was more effective and produced less aerosol than MQL. Similar work was carried out by Dhar et al. [7], although using AISI 1040 steel as work material. The authors noticed that lower temperatures were obtained with MQL, which might have had greater access to the interface, effectively cooling it due to the reduced contact length between chip and part. Kumar \&Ramamoorthy [12] assert that the superior ability of MQL in reducing temperature is due to the fact that heat is removed from the cutting zone by convection and evaporation, whereas in flood cutting convection is the only possible mean for heat transfer.

The aim of this work is to investigate the influence of the cutting parameters and cooling environment on the cutting tool temperature when turning AISI 4340 steel. Moreover, the effect of the cooling environment on the specific cutting energy is studied using an impact testing machine modified to a pendulum scratch testing machine. Using this device and having the heat capacity of the studied material in hand is possible to estimate the temperature associated with the chip formation mechanism and how this phenomenon is affected by cutting fluid application.the introduction of the paper should explain the nature of the problem, previous work, purpose, and the contribution of the paper. The contents of each section may be provided to understand easily about the paper.

\section{MATERIALS AND METHODS}

AISI 4340 steel was selected as work material. Initially, bars with diameter of $76.2 \mathrm{~mm}$ and length of $300 \mathrm{~mm}$ were subjected to full annealing (peak temperature of $930^{\circ} \mathrm{C}$ during five hours) to reach an average hardness value of $193 \mathrm{HV}$. Continuous turning trials were carried out on a computer numerical control lathe $(5.5 \mathrm{~kW}$ power and maximum rotational speed of 3500 rpm) employing TiCN/Al ${ }_{2} \mathrm{O}_{3} / \mathrm{TiN}$ coated tungsten carbide inserts (ISO grade P10-P30) as cutting tools. The inserts presented geometry coded CNMG 120408-GN and were mounted on a tool holder code PCLNR 2020K-12.

In order to measure the temperature of the cutting tools during the turning tests using the implanted thermocouple method (type $\mathrm{K}$ with wires possessing a diameter of $0.25 \mathrm{~mm}$ each), holes with nominal diameter of $1 \mathrm{~mm}$ and opposite to the rake face were produced in the inserts using electrical discharge machining (EDM), see Fig. 1. Figure 2 shows a photograph of a sample hole together with its most relevant dimensions.

The average depth of the EDMed holes is $3.7 \mathrm{~mm}$, therefore, considering that the thickness of the inserts is $4.76 \mathrm{~mm}$ the thermocouple hot junction was located $1.01 \mathrm{~mm}$ beneath the rake face. The thermocouples were connected to a Tektronix TEK DTM510 portable unit (operation range from from $-50^{\circ} \mathrm{C}$ to $1300^{\circ} \mathrm{C}$ and resolution of $1^{\circ} \mathrm{C}$ ).

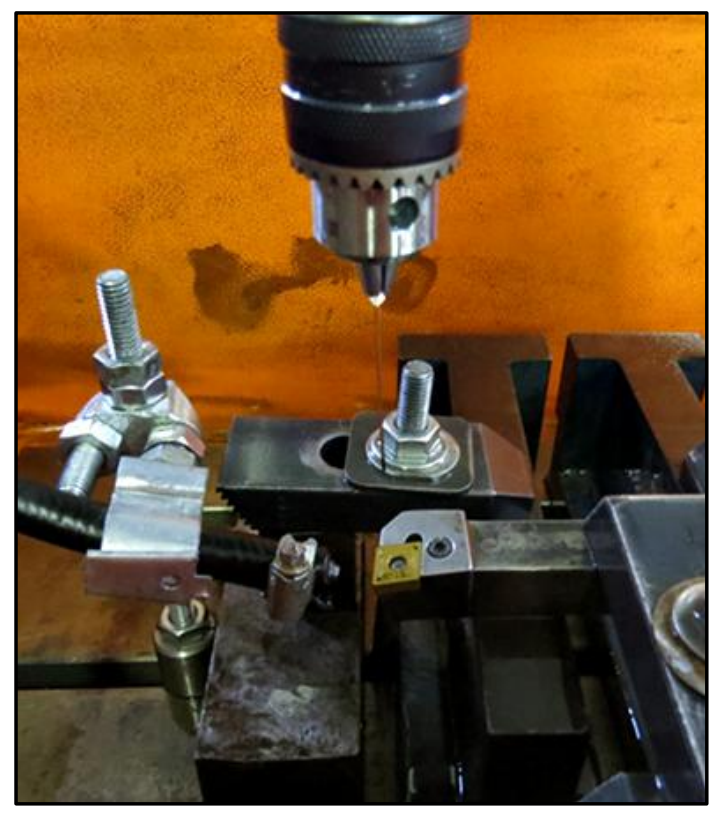

FIGURE 1: DRILLING OF INSERTS USING ELECTRICAL DISCHARGE MACHINING

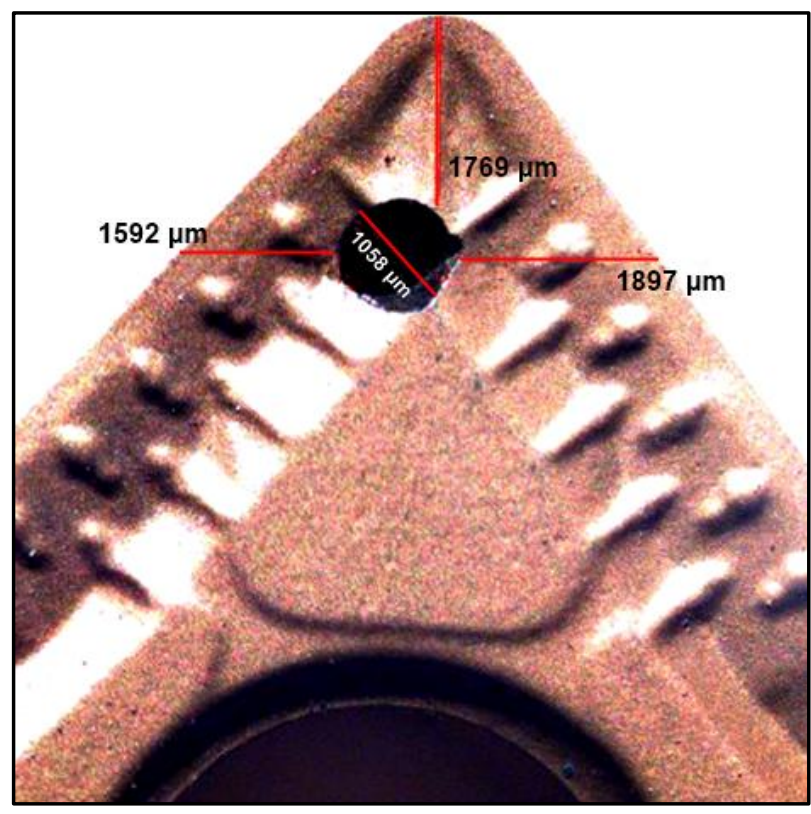

FIGURE 2: COATED TUNGSTEN CARBIDE INSERT WITH HOLE FOR THERMOCOUPLE EMBEDDING

Three cooling environments were employed during the turning tests: flooding (emulsion in a concentration of 5\% in water at a pressure of 1 bar and flow rate of $4.3 \ell / \mathrm{min}$ ), minimal quantity lubrication - MQL (vegetal based oil applied at a pressure of 5 bar and flow rate of $60 \mathrm{~m} \ell / \mathrm{h}$ using Accu-Lube MQL Box Applicator) and dry cutting. For all cooling environments, 
cutting fluid was applied at the tool-workpiece interface (clearance face). A fractional factorial experimental design was employed and the cutting conditions are depicted in Table 1. One test plus one replicate were performed for each condition.

TABLE 1

CUTTING CONDITIONS

\begin{tabular}{|c|c|c|c|c|}
\hline Level & $\begin{array}{c}\text { Cutting speed } \\
\mathbf{v}_{\mathbf{c}}(\mathbf{m} / \mathbf{m i n})\end{array}$ & $\begin{array}{c}\text { Feed rate } \\
\mathbf{f}(\mathbf{m m} / \mathbf{r e v})\end{array}$ & $\begin{array}{c}\text { Depth of cut } \\
\mathbf{a}_{\mathbf{p}}(\mathbf{m m})\end{array}$ & Cooling method \\
\hline- & 150 & 0.15 & 0.5 & Flooding \\
\hline 0 & 200 & - & 1.0 & MQL \\
\hline+ & 250 & 0.3 & 1.5 & Dry \\
\hline
\end{tabular}

Additionally to the turning tests, single pass pendulum scratch tests were performed using a modified Gunt Hamburg WP410 impact machine. Instead of an indenter, however, the same tool holder and inserts used in the turning trials were attached to the pendulum. The aim of this test is to measure the specific cutting energy associated with chip formation and verify whether this test can replace force measurement using a dynamometer, which is a much more expensive equipment. Figure 3(a) shows the modified impact machine and Fig. 3(b) presents the tool holder attached to the pendulum. AISI 4340 steel specimen with $10 \times 20 \times 50 \mathrm{~mm}$ (Fig. 3c) were taken from the bars after the turning tests and their mass values were recorded before and after each scratch test using a Mettler Toledo AB204 precision balance (range from $10 \mathrm{~g}$ to $210 \mathrm{~g}$ and resolution of $0.0001 \mathrm{~g})$.

The same cooling environments used in the turning tests (flooding, MQL and dry cutting) were employed in the pendulum scratch tests, nevertheless, the specimen holder was adjusted in order to allow the removal of a maximum cross section of 1 $\mathrm{mm}^{2}$. Therefore, the potential energy associated with cutting (chip formation plus ploughing) and sliding can be used to estimate cutting fluid efficiency.

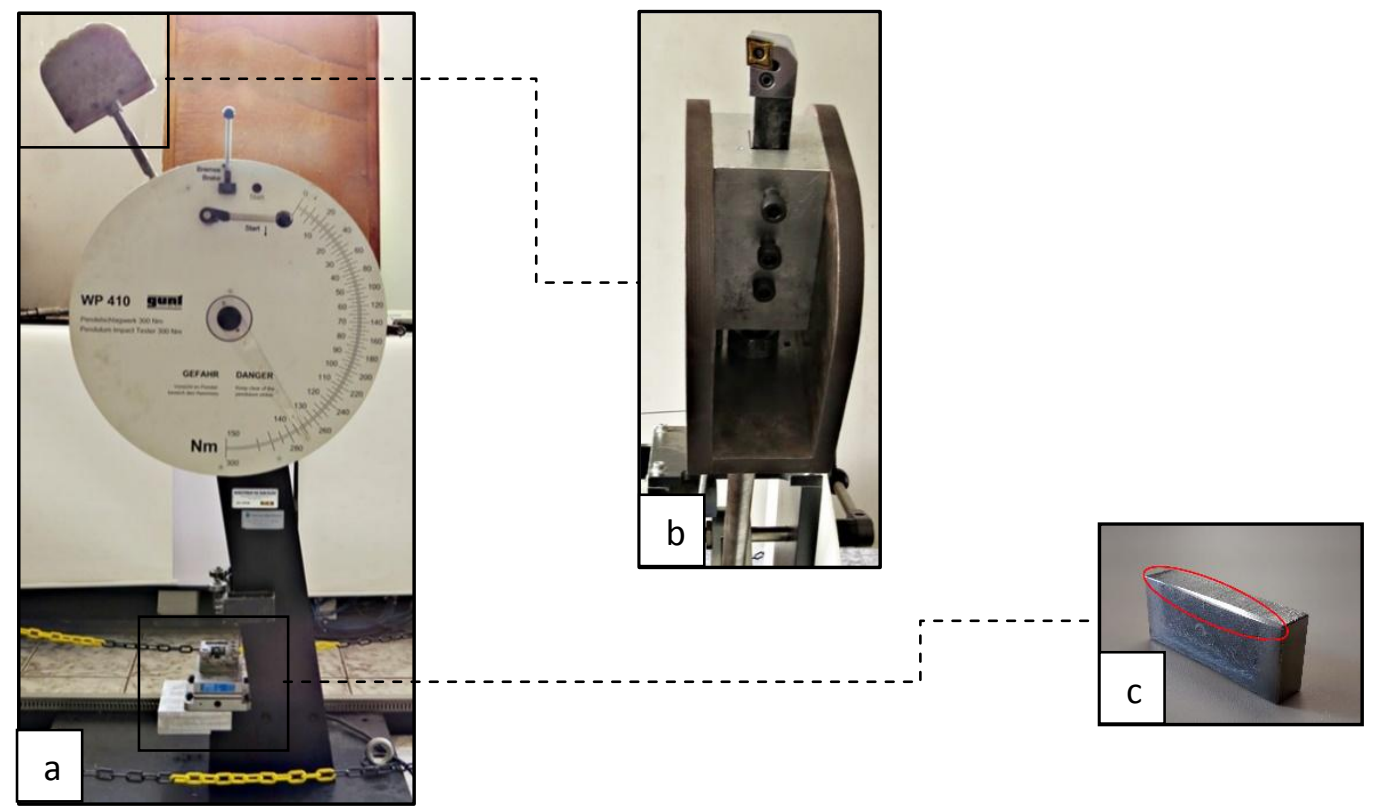

\section{FIGURE 3: MODIFIED IMPACT TESTING MACHINE (A) WITH A DETAIL OF THE TOOL HOLDER ATTACHED TO THE PENDULUM (B) AND A SPECIMEN AFTER TESTED (C)}

\section{RESULTS AND DISCUSSION}

A preliminary test under constant cutting condition (cutting speed of $200 \mathrm{~m} / \mathrm{min}$, feed rate of $0.3 \mathrm{~mm} / \mathrm{rev}$ and depth of cut of $1 \mathrm{~mm}$ ) was carried out for each cooling environments in order to assess the time required for temperature stabilization at the thermocouple location. For this purpose, the embedded thermocouple was connected to a signal amplifier integrated into a Tektronix TDS1001C-EDU oscilloscope. Figure 4 shows that when flood turning, temperature remains stable after a sudden increase, while when cutting with MQL temperature stabilizes after approximately $20 \mathrm{~s}$ and for dry cutting a steady 
temperature value is not achieved after turning for $24 \mathrm{~s}$. Based on these data and in order to avoid the influence of tool wear, tool temperature was collected after $15 \mathrm{~s}$ for all tested conditions.

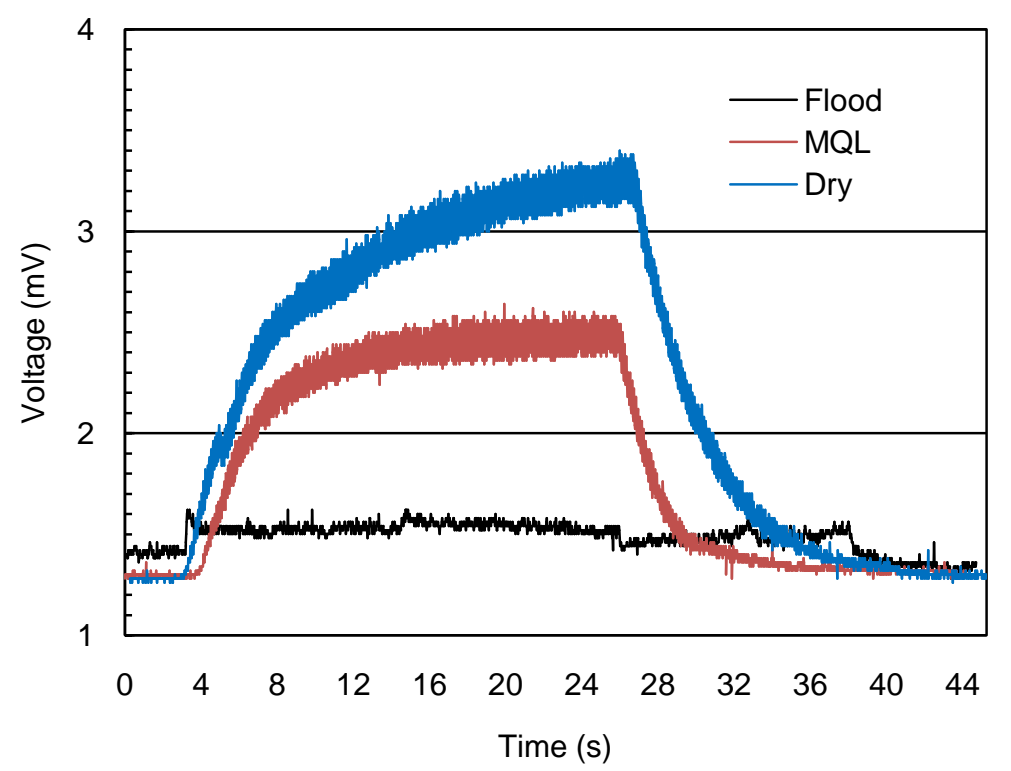

\section{Figure 4: TEMPERATURE (VOLTAGE) EVOLUTION AGAINST CUTTING TIME}

The influence of cutting speed and cooling environment on cutting tool temperature is represented in Fig. 5. Irrespectively of the cutting speed tested, lowest tool temperatures are obtained with flooding, followed by MQL and by dry cutting. The higher convective coefficient of the cutting fluid applied as a flood together with the reduction of friction by the mineral oil present in the emulsion promotes a steeper temperature reduction. An intermediate condition is observed when minimal quantity lubrication is applied, while the highest temperatures in dry turning indicate that convection to air is insufficient to promote a considerable temperature decrease (under forced convection, the heat transfer coefficient of water is approximately 10 - 20 times higher than that of hot air).

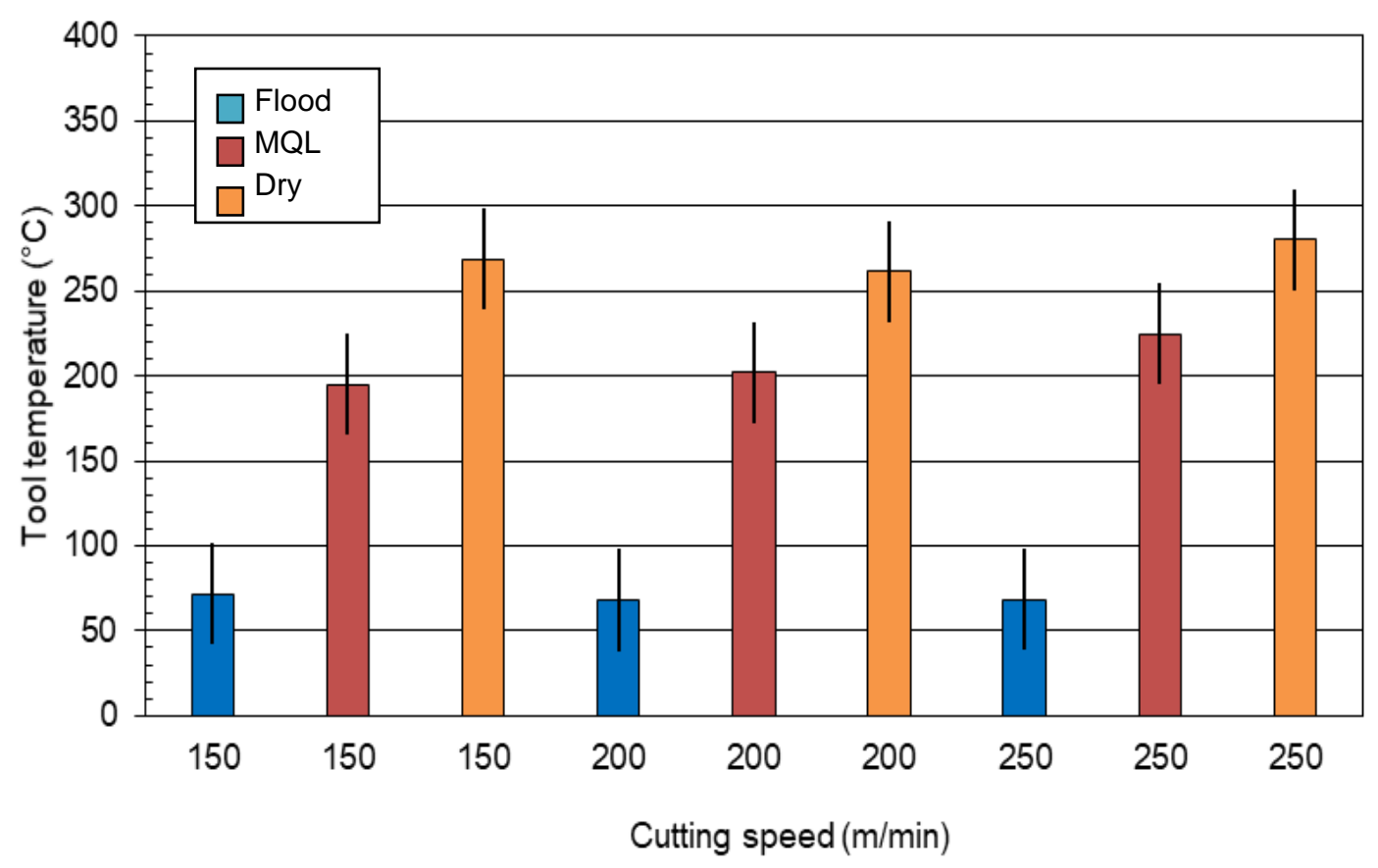

FIGURE 5: EFFECT OF CUTTING SPEED AND COOLING ENVIRONMENT ON TOOL TEMPERATURE $\left(\mathrm{f}=0.3 \mathrm{~mm} / \mathrm{rev}\right.$ and $\mathrm{a}_{\mathrm{p}}=1$ mm) 
Table 2 summarises the analysis of variance (ANOVA) results for the influence of cutting speed and cooling environment on temperature (confidence level of $95 \%$ ), where feed rate and depth of cut were kept constant $\left(\mathrm{f}=0.3 \mathrm{~mm} / \mathrm{rev}\right.$ and $\left.\mathrm{a}_{\mathrm{p}}=1.0 \mathrm{~mm}\right)$. It can be noted that only cooling environment possesses a significant effect. Within the cutting range tested, the influence of both cutting speed and the interaction between cutting speed and cooling environment are statistically negligible. This behaviour can be explained by the fact that the selected temperature measuring technique is less sensitive to cutting speed owing to the fact that when the latter is increased, chip thickness is reduced, therefore, the heat source moves away from the thermocouple location.

TABLE 2

ANOVA FOR TEMPERATURE CONSIDERING CUTTING SPEED AND COOLING ENVIRONMENT

\begin{tabular}{|c|c|}
\hline Factor & p-value \\
\hline Cutting speed $\left(\mathrm{v}_{\mathrm{c}}\right)$ & 0.073 \\
\hline Cooling environment & 0.000 \\
\hline $\mathrm{v}_{\mathrm{c}}$ *cooling environment $^{-}$ & 0.269 \\
\hline
\end{tabular}

The influence of feed rate (f) and depth of cut $\left(a_{p}\right)$ on cutting tool temperature for distinct cooling environments is shown in Fig. 6. Increasing feed rate and depth of cut leads to large shear plane areas and, consequently, higher shear stresses are required, thus resulting in higher temperatures in the cutting zone. Similarly to Fig. 5, cutting fluid applied as a flood was responsible for lower tool temperatures, followed by MQL and dry cutting. One spurious result was observed when turning under flooding using a depth of cut of $1.5 \mathrm{~mm}$, where the temperature recorded for $\mathrm{f}=0.15 \mathrm{~mm} / \mathrm{rev}$ was higher than that for $\mathrm{f}=0.3 \mathrm{~mm} / \mathrm{rev}$. One possible explanation for such behaviour may be the undesired change in the position of the thermocouple used in the test at $\mathrm{f}=0.3 \mathrm{~mm} / \mathrm{rev}$ farther from cutting zone.

The analysis of variance considering the influence of depth of cutting and cooling environment is summarized in Table 3, however, due to the selected experimental design; it is presented separately for each feed rate. Depth of cut and cooling environment significantly affect cutting tool temperature, irrespectively of the feed rate employed. As far as the interaction between depth of cut and cooling environment is concerned, however, it is statistically significant for the highest feed rate only. A paired t-test was performed for tool temperature measured at different feed rates and the result indicated that they are statistically significant within a $95 \%$ confidence level.

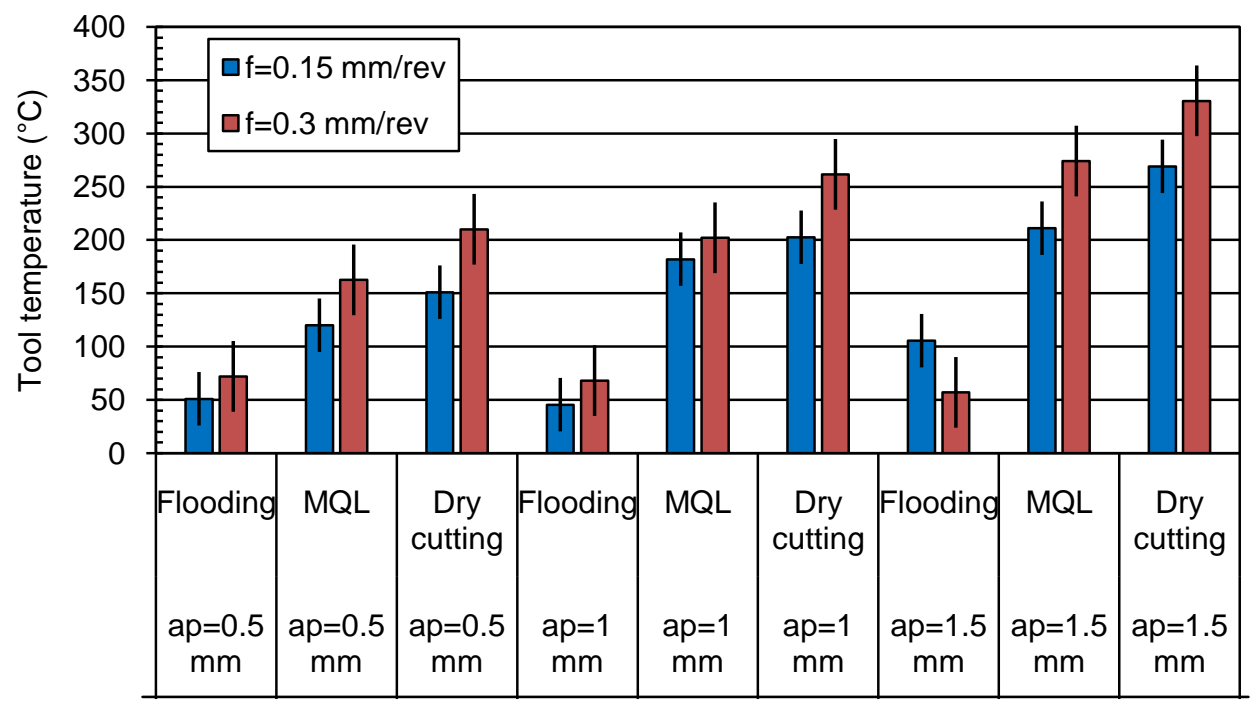

Cutting condition

FIGURE 6: EFFECT OF FEED RATE AND DEPTH OF CUT ON TOOL TEMPERATURE $\left(\mathrm{v}_{\mathrm{c}}=\mathbf{2 0 0} \mathrm{m} / \mathrm{min}\right)$ 
TABLE 3

ANOVA FOR TEMPERATURE CONSIDERING DEPTH OF CUT AND COOLING METHOD

\begin{tabular}{|c|c|c|}
\hline Factor & $\begin{array}{c}\mathbf{p} \text {-value } \\
(\mathbf{f}=\mathbf{0 . 1 5} \mathbf{~ m m} / \mathbf{r e v})\end{array}$ & $\begin{array}{c}\mathbf{p} \text {-value } \\
(\mathbf{f}=\mathbf{0 . 3 0} \mathbf{~ m m} / \mathbf{r e v})\end{array}$ \\
\hline Depth of cut $\left(\mathrm{a}_{\mathrm{p}}\right)$ & 0.002 & 0.000 \\
\hline Cooling environment & 0.000 & 0.000 \\
\hline $\mathrm{a}_{\mathrm{p}} *$ cooling environment & 0.365 & 0.003 \\
\hline
\end{tabular}

Following the cutting temperature tests, specific cutting energy was measured employing the equipment depicted in Figure 3 , however, it is important to point out the fact that the same tool holder and insert geometry as well as tool grade employed in the temperature measurements were used. AISI 4340 steel specimens were mounted in order to allow the removal of a maximum cross section with $1 \mathrm{~mm}^{2}$ during the test, which represents a two-fold increase in the chip cross section area in comparison with the most severe cutting condition employed in the cutting temperature measurements $\left(f \times a_{p}=0.3 \times 1.5=0.45\right.$ $\mathrm{mm}^{2}$ ). By converting the gravitational potential energy into kinetic energy the pendulum speed was calculated to be 276 $\mathrm{m} / \mathrm{min}$, i.e., slightly above the highest cutting speed used in the temperature measurement trials $\left(\mathrm{v}_{\mathrm{c}}=250 \mathrm{~m} / \mathrm{min}\right)$.

The average specific cutting energy $(\mathrm{u})$ for each cooling environment is presented in Fig. 7, where it can be noted that the highest value $(\mathrm{u}=418.1 \mathrm{~J} / \mathrm{g})$ was recorded when testing under flooding, followed by cutting under MQL ( $\mathrm{u}=366.9 \mathrm{~J} / \mathrm{g}$ ) and dry cutting $(\mathrm{u}=347.4 \mathrm{~J} / \mathrm{g})$. Two sample t-tests were performed and the results indicated that the specific cutting energy obtained under flooding is not equal to dry cutting within a significance level of 5\%, however, the difference between flooding and MQL and between MQL and dry cutting is not statistically significant. The specific cutting energy can be considered as the sum of three components associated with chip formation, ploughing and sliding [13]. These findings indicate that the low oil concentration in the emulsion (5\%) does not offer an appreciable contribution towards the reduction of the friction coefficient. Inversely, the high water concentration plays a key role in transferring heat away from the tool-workpiece interface, thus preventing temperature elevation (as can be seen in Figures 5 and 6) and the consequent reduction in the shear strength of the work material. When minimal quantity lubrication is applied, however, the intermediate specific cutting energy value suggests that the access of oil droplets in the tool-workpiece interface is improve and less energy is spent in sliding due to the reduction in the friction coefficient. Finally, lowest specific cutting energy is obtained when performing the pendulum scratch test without cutting fluid application, probably owing to the fact that the temperature increase promotes the softening of the work material (reduction in the specific cutting energy associated with chip formation).

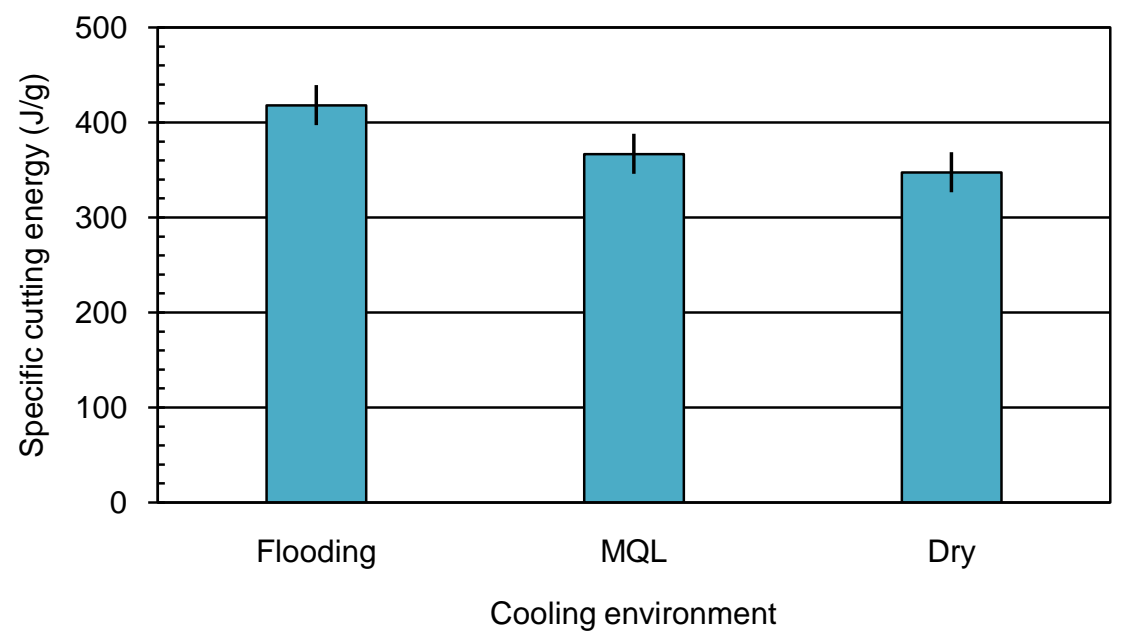

FIGURE 7: EFFECT OF COOLING ENVIRONMENT ON THE SPECIFIC CUTTING ENERGY

Considering that the specific cutting energy is equivalent to the specific heat capacity $(\mathrm{m} \cdot \mathrm{c} \cdot \Delta \mathrm{T})$, the temperature change associated with chip formation can be estimated. In the case of the scratch tests performed without cutting fluid, the average specific cutting energy is $\mathrm{u}=347.4 \mathrm{~J} / \mathrm{g}$. Estimating the specific heat capacity of steel as $\mathrm{c}=0.466 \mathrm{~J} / \mathrm{gK}$ results in a temperature change of $745 \mathrm{~K}$ (or $745^{\circ} \mathrm{C}$ ) when removing a cross section of $1 \mathrm{~mm}^{2}$ at a speed of $276 \mathrm{~m} / \mathrm{min}$, while the temperature recorded by the thermocouple embedded $1.01 \mathrm{~mm}$ beneath the rake face of the cutting tool recorded $330.5^{\circ} \mathrm{C}$ when turning at a cutting speed of $\mathrm{v}_{\mathrm{c}}=200 \mathrm{~m} / \mathrm{min}$ and removing chips with a cross section of $0.45 \mathrm{~mm}^{2}\left(\mathrm{f}=0.3 \mathrm{~mm} / \mathrm{rev}\right.$ and $\left.\mathrm{a}_{\mathrm{p}}=1.5 \mathrm{~mm}\right)$. 
Considering the difference in the shear areas for both cases and distance between the tool-chip interface and thermocouple position, the difference between the calculated temperature change and value measured by the thermocouple is quite plausible.

\section{CONCLUSION}

After conducting continuous turning tests on AISI 4340 steel using coated tungsten carbide tools under flooding, minimal quantity lubrication (MQL) and dry cutting in order to measure the cutting tool temperature (using the implanted thermocouple method) and performing pendulum scratch tests on a modified impact testing machine in order to assess the specific cutting energy associated with each cooling environment, the following conclusions can be drawn:

- As far as the influence of the cutting parameters is concerned, temperature in the cutting tool increased with the elevation of cutting speed, feed rate and depth of cut, however, the effect of cutting speed was considered not statistically significant with a confidence level of $95 \%$. This behaviour can be explained by the fact that the tool-chip contact area is reduced as cutting speed is elevated, therefore the heat source is moved farther from the thermocouple location.

- Cooling environment statistically affected cutting tool temperature and lowest tool temperatures were recorded when flood turning, followed by minimal quantity lubrication and dry turning.

- Inversely, lowest specific cutting energy was obtained during the dry pendulum tests, thus suggesting that the higher temperature achieved under this condition aid the softening of the work material and the reduction of its shear strength. Highest specific cutting energy was recorded for the tests under flooding and intermediate results were achieve using minimal quantity lubrication, which indicates that the oil droplets produced by MQL are capable of reducing the friction coefficient and, consequently, the fraction of the specific energy associated with sliding.

- The modified pendulum scratch test allowed the calculation of the temperature associated with the chip formation mechanism.

\section{ACKNOWLEDGEMENTS}

The authors would like to thank the following research agencies in Brazil for supporting this research project: CNPq, CAPES and FAPEMIG.

\section{REFERENCES}

[1] F.W. Taylor,On the art of cutting metals, New York: The American Society of Mechanical Engineers, 1906. Available at: <http://ir.library.oregonstate.edu/xmlui/handle/1957/21006>. Access on the 7 October 2014.

[2] M. Hadad, and B.Sadeghi, "Minimum quantity lubrication-MQL turning of AISI 4140 steel alloy”,J. Cleaner Prod., vol. 54, pp 332343, 2013.

[3] V.S. Sharma, M. Dogra, and N.M.Suri,“Cooling techniques for improved productivity in turning”,Int. J. Machine Tools Manuf., vol. 49(6), pp. $435-453,2009$.

[4] S. Kalpakjian, and S.R.Schmid, Manufacturing Engineering and Technology. New Jersey: Prentice Hall, 2010.

[5] S.A. Lawal, I.A. Choudhury, and Y.Nukman, "Developments in the formulation and application of vegetable oil-based metalworking fluids in turning process", Int. J. Adv. Manuf. Technol., vol. 67(5-8),pp. 1765-1776, 2013.

[6] I.B. Abhang, and M. Hameedullah, "Experimental investigation of minimum quantity lubricants in alloy steel turning", Int.J. Eng. Sci. Technol., vol. 2(7), pp. 3045-3053, 2010.

[7] N.R. Dhar, M.W. Islam, S. Islam, and M.H.A. Mithu, "The influence of minimum quantity of lubrication (MQL) on cutting temperature, chip and dimensional accuracy in turning AISI-1040 steel”, J. Mater. Process. Technol., vol.171(1), pp 93-99, 2006.

[8] N. Boubekri, V. Shaikh, and P.R. Foster. "A technology enabler for green machining: minimum quantity lubrication (MQL)". Journal of Manufacturing Technology Management. 2010; 21(5): 556-566.

[9] G.D. Revankar, R. Shetty, S.S. Rao, and V.N.Gaitonde, "Analysis of surface roughness and hardness in titanium alloy machining with polycrystalline diamond tool under different lubricating modes", Mater. Res., vol. 17(4), pp. 1010-1022, 2014.

[10] A.S. Varadarajan, P.K. Philip, and B. Ramamoorthy, "Investigations on hard turning with minimal cutting fluid application (HTMF) and its comparison with dry and wet turning”,Int. J. Machine Tools Manuf., vol. 42(2), pp. 193-200, 2002.

[11] K-M. Li, and S.Y. Liang, "Performance profiling of minimum quantity lubrication in machining”, Int. J. Adv. Manuf. Technol., vol.35(3-4), pp. 226-233, 2007.

[12] C.R.V. Kumar, and B. Ramamoorthy, "Performance of coated tools during hard turning under minimum fluid application", Journal of Materials Processing Technology. 2007; 185(1-3): 210-216.

[13] S. Malkin. Grinding technology: Theory and applications of machining with abrasives, Nova York: John Wiley \& Son Limited, 1989. 